\title{
Knowledge on risk factors of uterine prolapse among reproductive age group women of Bajrabarahi Municipality of Lalitpur, Nepal
}

\author{
Devendra Raj $\operatorname{Singh}^{1} *$, Sandhya Lama ${ }^{1}$, Santosh Maharjan ${ }^{2}$
}

\footnotetext{
${ }^{1}$ Department of Public Health, Asian College for Advance Studies, Purbanchal University, Satdobato, Lalitpur, Nepal

${ }^{2}$ Nepal Fertility Care Center, Kathmandu, Nepal
}

Received: 10 August 2016

Accepted: 06 September 2016

\section{*Correspondence:}

Mr. Devendra Raj Singh,

E-mail: devendrars@hotmail.co.uk

Copyright: (C) the author(s), publisher and licensee Medip Academy. This is an open-access article distributed under the terms of the Creative Commons Attribution Non-Commercial License, which permits unrestricted non-commercial use, distribution, and reproduction in any medium, provided the original work is properly cited.

\begin{abstract}
Background: Pelvic organ prolapse (POP) is a most common gynecological health problem contributing to maternal morbidity and mortality among women of reproductive age in developing countries. In Nepal prevalence of uterus prolapse among reproductive age women is around 17-27\%. Still large numbers of rural Nepalese women are deprived of access to early diagnosis and quality treatment services related uterus prolapse. The present study was conducted with the aims to assess knowledge on risk factors on uterine prolapse among the reproductive age group of women who have at least one child below five years of age and residing at Bajrabarahi municipality of Lalitpur district.

Methods: This is a cross sectional descriptive study. Total 185 individuals were randomly selected from the list of safe motherhood register book of Bajrabarahi municipality for the interview. Semi-structured questionnaire was used as tools to collect data from study participants. Data collected was entered in Epi-data and data analysis was done using SPSS 16.0 version. Bivariate analysis was done using Chi-Square test to find the association between the selected variables of the study.

Results: The study results shows that out of total $46.5 \%$ of respondents have adequate knowledge and $53.5 \%$ of respondents have inadequate knowledge regarding risk factors of uterus prolapse. The study results explicitly reflects the knowledge on risk factors of uterus prolapse is significantly associated with the age of respondent $(p=0.021)$, age at marriage of respondents $(p=0.011)$, education status of respondents $(p=0.001)$ and age at first child birth of respondent $(\mathrm{p}=0.001)$.

Conclusions: Though majority of respondents have heard about uterus prolapse, very few participants have in-depth or adequate knowledge about risk factors of uterus prolapse. Still extensive efforts of government and nongovernment organizations are essential to improve maternal health status of rural Nepalese women.
\end{abstract}

Keywords: Uterus prolapse, Knowledge, Risk factors, Reproductive age women, Nepal

\section{INTRODUCTION}

Pelvic organ prolapse (POP) is a most common gynecological health problem contributing to maternal morbidity and mortality among women of reproductive age in developing countries. ${ }^{1,2}$ The global estimates reflect prevalence of pelvic organ prolapse (POP) among women below 45 years of age ranges from $2-20 \%{ }^{3}$ Prevalence of POP based on symptoms ranges from 3-6\% and up $50 \%$ when defined by vaginal examination. ${ }^{4}$ In Nepal, prevalence of uterus prolopase (UP) among reproductive age women is around $17-27 \% .^{5}$ Despite the governmental and non- governmental organizations efforts in creating awareness and supporting in treatment facilities of UP both at rural and urban setting, still large numbers of Nepalese women are unaware about UP and have low access to UP diagnosis and treatments facilities. $^{6,7}$

Family health division under ministry of health has developed operational guidelines in 2009 for the management of UP and also collaborated with National 
Health Education, Information, Communication Center for communication of governmental preventive interventions of UP among public. ${ }^{8}$ However, the expected reduction in UP cases has been not achieved and still community based additional efforts are essential to gain substantial reduction of UP among Nepalese rural women. ${ }^{6,7}$ The consequences of UP does not only affects women health and quality of life, it has negative consequences on family health and socio-economic status as well.

Studies from different administrative regions of Nepal shows that in Siraha and Saptari districts of terai region has found high prevalence of UP among reproductive age women to be $30 \%$ and $42 \%$ respectively. ${ }^{9}$ According to National Alliance for Pelvic Organ Prolapse Management- Nepal, UP prevalence rate were found to be higher among regions, caste and ethnic groups where women and girls are exposed to higher level of gender based discriminations. ${ }^{10,11}$

Adolescent pregnancy, lack of rest during and immediately after pregnancy - including carrying heavy loads, improper birthing practices used by unskilled birth attendants, poor nutrition, frequent pregnancies and pregnancies close together due to lack of access to contraception are major risk factors associated with UP. ${ }^{4,712,13}$ In Nepal, child marriage and adolescent pregnancy are high among rural females. ${ }^{14}$

According to Nepal Demographic and Health Survey (2011) reflects that of the $29.1 \%$ of adolescent girls reporting recent sexual activity, $28.8 \%$ were married. NDHS 2011 also shows that $10.5 \%$ of 17 -year-old girls, $4.9 \%$ of 16 years old girls and $0.9 \%$ of 15 years old girls were pregnant or had given birth to their first child. ${ }^{14}$ Moreover, majority of Nepalese women work in the informal sector and do not have access to paid maternity leave or social security benefits. ${ }^{11}$ Most of them are working in conditions where they have to lift heavy objects and carry heavy loads that can strain the pelvic muscles particularly during pregnancy and postnatal period. $^{11}$

Also, study conducted among Nepalese women by UNFPA in 2013 shows those women who had undergone surgery for uterine prolapse found to have rested only 7 20 days after giving birth, where government have recommended for at least 6 week postnatal rest period after delivery. ${ }^{15}$ Nearly $98 \%$ of rural women from Terai, Hills and Mountain region reported carrying heavy loads following giving birth. ${ }^{5,15}$ Such activities and circumstances are highly contributing in raising prevalence of UP among Nepalese women. ${ }^{5,15,16}$ Considering this situation, the present study was conducted with the aims to assess knowledge on risk factors on uterine prolapse among the reproductive age group of women who have at least one child below five years of age. The study also intended to identify the factors influencing knowledge on risk factors of UP.

\section{METHODS}

This is a cross sectional descriptive study. The calculated sample size was 190 considering the proportion of adequate knowledge level 0.37 , confidence level $95 \%$ and error 7\%. Among 190 study participants 5 individuals were dropout during interview process. Thus total 185 individuals were considered as study participants. The study participants were randomly selected from the list of safe motherhood register book of Bajrabarahi municipality. An interview method was adopted and Semi-structured questionnaire was used as tools to collect data from study participants. The data collection questionnaire was translated from English to Nepali language. Data collected was entered in Epi-data and data analysis was done using SPSS 16.0 version. Bivariate analysis was done using Chi-Square test to find the association between the selected variables of the study. The study was formally approved from Asian college for advance studies research committee, Purbanchal University. Verbal informed consent was taken from each respondent prior to interview. None of the respondent was forced to participate in the study and privacy of information gathered was assured.

\section{RESULTS}

\section{Socio-demographic characteristics of respondents}

The study findings in Table 1 shows majority of the respondents were of age group 25-29 (47\%) followed by $20-24(26.5 \%)$ with the mean age 26.7 years \pm 4.69 SD. About $21.2 \%$ respondents were illiterate and $22.16 \%$ have basic informal education whereas 13.51, 29.19\% and $14.05 \%$ have attended primary, secondary and higher education respectively. In the same way, $49.7 \%$ respondents were either housewife or engaged in agriculture, $35.7 \%$ were wages based laborers, $9.2 \%$ have their own business and only $5.4 \%$ of respondents were involved in public service.

\section{Obstetric variables of respondents}

The study results in Table 2 presents out of total respondents $42.16 \%$ of respondents were married at early age i.e. between ages of 12-19 years. Similarly, about $29 \%$ respondent had already first child before age of 19 years of age. Also, more $28 \%$ of respondents had second child with less than 2 years of child spacing.

\section{Study participants responses regarding knowledge variables of $U P$}

The results in Table 3 shows nearly $85 \%$ of respondents have heard about Uterus prolapse however out that about $28 \%$ of respondent were not able to responses even single risk factors associated to uterus prolapse. Similarly, about $68 \%$ of respondents were not able to response any single sign and symptoms of uterus prolapse 
Table 1: Socio-demographic characteristics of respondent.

\begin{tabular}{|lll|}
\hline Socio demographic variables & $\begin{array}{l}\text { Frequency } \\
(\mathbf{n})\end{array}$ & $\begin{array}{l}\text { Percent } \\
(\%)\end{array}$ \\
\hline Age (Years) & 7 & 3.78 \\
\hline $15-19$ & 49 & 26.49 \\
\hline $20-24$ & 87 & 47.03 \\
\hline $25-29$ & 24 & 12.97 \\
\hline $30-34$ & 18 & 9.73 \\
\hline $35-39$ & & \\
\hline Caste & 20 & 10.81 \\
\hline Brahmin & 25 & 13.51 \\
\hline Chhettri & 72 & 38.92 \\
\hline Newar & 68 & 36.76 \\
\hline Janjati & & \\
\hline Type of family & 123 & 66.49 \\
\hline Nuclear & 62 & 33.51 \\
\hline Joint & & \\
\hline Educational status & 41 & 22.16 \\
\hline Literate (informal education) & 39 & 21.08 \\
\hline Illiterate & 25 & 13.51 \\
\hline Primary level & 54 & 29.19 \\
\hline Secondary level & 26 & 14.05 \\
\hline Higher level & & \\
\hline Occupation & 92 & 49.73 \\
\hline Housewife/agriculture & 66 & 5.41 \\
\hline Wages based labour & 10 & \\
\hline Public service & 17 & \\
\hline Own business & & \\
\hline & & \\
\hline
\end{tabular}

Table 2: Obstetric variables of respondents.

\begin{tabular}{|lcl|}
\hline $\begin{array}{l}\text { Obstetric variables } \\
\text { Age at 1st menstruation (years) }\end{array}$ & \\
\hline Below 10 & 3 & 1.62 \\
\hline $11-12$ & 62 & 33.51 \\
\hline $13-14$ & 89 & 48.11 \\
\hline $14-16$ & 31 & 16.76 \\
\hline Age at marriage (years) & \\
\hline $12-15$ & 23 & 12.43 \\
\hline $16-19$ & 55 & 29.73 \\
\hline $20-23$ & 84 & 45.41 \\
\hline $24-27$ y & 23 & 12.43 \\
\hline Age at 1st child birth (years) & \\
\hline $10-14$ & 3 & 1.62 \\
\hline $15-19$ & 50 & 27.03 \\
\hline $20-24$ & 85 & 45.95 \\
\hline $25-29$ & 42 & 22.70 \\
\hline $30-34$ & 5 & 2.70 \\
\hline Birth spacing of child (years) & \\
\hline Below 2 & 23 & 28.40 \\
\hline $3-5$ & 39 & 48.15 \\
\hline Above 5 & 19 & 23.46 \\
\hline Total & 81 & \\
\hline History of abortion & & 2.70 \\
\hline Yes & 5 & 97.30 \\
\hline No & 180 & \\
\hline
\end{tabular}

Table 3: Study participants response regarding knowledge variables of UP.

\begin{tabular}{|c|c|c|}
\hline Variables & Frequency & Percent \\
\hline \multicolumn{3}{|l|}{ Heard about uterine prolapse } \\
\hline Yes & 156 & 84.32 \\
\hline No & 29 & 15.68 \\
\hline \multicolumn{3}{|c|}{$\begin{array}{l}\text { Risk factors of uterine prolapse (multiple } \\
\text { response) } n=156\end{array}$} \\
\hline Frequent child bearing & 25 & 16.03 \\
\hline $\begin{array}{l}\text { Doing heavy works during } \\
\text { postnatal period }\end{array}$ & 108 & 69.23 \\
\hline $\begin{array}{l}\text { Giving birth at early and too late } \\
\text { age }\end{array}$ & 20 & 12.82 \\
\hline $\begin{array}{l}\text { Delivery conducted by untrained } \\
\text { person }\end{array}$ & 1 & 0.64 \\
\hline $\begin{array}{l}\text { Nutritional deficiency during post } \\
\text { natal period }\end{array}$ & 9 & 5.77 \\
\hline Frequent and risky abortion & 17 & 10.90 \\
\hline Don't know & 43 & 27.56 \\
\hline \multicolumn{3}{|c|}{$\begin{array}{l}\text { Sign and symptom of uterine prolapse (multiple } \\
\text { response) }\end{array}$} \\
\hline $\begin{array}{l}\text { Feeling of something coming } \\
\text { down }\end{array}$ & 13 & 8.33 \\
\hline Pulling or heavy feeling in pelvis & 23 & 14.74 \\
\hline $\begin{array}{l}\text { Vaginal bleeding or increased } \\
\text { discharge }\end{array}$ & 13 & 8.33 \\
\hline Difficult in walking & 20 & 12.82 \\
\hline Constipation & 16 & 10.26 \\
\hline Don’t know & 106 & 67.95 \\
\hline
\end{tabular}

Table 4: Knowledge on risk factors of uterus prolapse among respondents.

\begin{tabular}{|lll|}
\hline Knowledge level & Frequency & Percent \\
\hline $\begin{array}{l}\text { Inadequate knowledge } \\
(<75 \% \text { score })\end{array}$ & 99 & 53.5 \\
\hline $\begin{array}{l}\text { Adequate knowledge }(>75 \% \\
\text { score })\end{array}$ & 86 & 46.5 \\
\hline Total & $\mathbf{1 8 5}$ & $\mathbf{1 0 0}$ \\
\hline
\end{tabular}

\section{Knowledge on risk factors of uterus prolapse among respondents}

The results in the Table 4 shows out of total respondents $46.5 \%$ of respondents have adequate knowledge regarding risk factors of uterus prolapse and $53.5 \%$ of respondents have inadequate knowledge about risks factors of uterus prolapse.

Table 5 presents the multivariate analysis of selected variables with knowledge categories on risk factors of uterus prolapse. The results shows, age of respondents, age at marriage of respondents, education status of respondents, age at first child birth of respondent, were significantly associated (p-value <0.05) with the knowledge on risk factors of uterus prolapse among respondents. 
Table 5: Chi-square test of association between UP knowledge categories and selected study variables.

\begin{tabular}{|c|c|c|c|c|c|c|}
\hline \multirow{2}{*}{$\begin{array}{l}\text { Variables } \\
\text { Age of the respondent (years) }\end{array}$} & \multicolumn{2}{|c|}{ Inadequate knowledge } & \multicolumn{2}{|c|}{ Adequate knowledge } & \multirow[t]{2}{*}{$x^{2}$} & \multirow[t]{2}{*}{ p-value } \\
\hline & $\mathbf{N}$ & $\%$ & $\mathbf{N}$ & $\%$ & & \\
\hline & 7 & 100 & 0 & 0 & & \\
\hline $20-24$ & 21 & 42.9 & 28 & 57.1 & & \\
\hline $25-29$ & 44 & 50.6 & 43 & 49.4 & 11.54 & 0.021 \\
\hline $30-34$ & 17 & 70.8 & 7 & 29.2 & & \\
\hline $35-39$ & 10 & 55.6 & 8 & 44.4 & & \\
\hline \multicolumn{7}{|l|}{ Age at marriage (years) } \\
\hline $12-15$ & 16 & 69.6 & 7 & 30.4 & & \\
\hline $16-19$ & 31 & 56.4 & 24 & 43.6 & 11.14 & 0.011 \\
\hline $20-23$ & 35 & 41.7 & 49 & 58.3 & & \\
\hline $24-27$ & 17 & 73.9 & 6 & 26.1 & & \\
\hline \multicolumn{7}{|l|}{ Family type } \\
\hline Nuclear & 67 & 54.4 & 56 & 45.5 & 0.13 & 0.713 \\
\hline Joint & 32 & 51.6 & 30 & 48.3 & & \\
\hline \multicolumn{7}{|l|}{ Educational status } \\
\hline Literate & 27 & 65.9 & 14 & 34.1 & & \\
\hline Illiterate & 28 & 71.8 & 11 & 28.2 & & \\
\hline Primary level & 17 & 68 & 8 & 32 & 22.43 & 0.001 \\
\hline Secondary level & 18 & 33.3 & 36 & 66.7 & & \\
\hline Higher level & 9 & 34.6 & 17 & 65.3 & & \\
\hline \multicolumn{7}{|l|}{ Occupation } \\
\hline Housewife/agriculture & 49 & 53.2 & 43 & 46.7 & & \\
\hline Labour & 36 & 54.6 & 30 & 45.4 & 3.1 & 0.375 \\
\hline Service & 3 & 30 & 7 & 70 & & \\
\hline Business & 11 & 64.7 & 6 & 35.3 & & \\
\hline \multicolumn{7}{|l|}{ Age at 1st child birth (years) } \\
\hline $10-14$ & 0 & 0 & 3 & 100 & & \\
\hline $15-19$ & 37 & 74 & 13 & 26 & & \\
\hline $20-24$ & 32 & 37.6 & 53 & 62.3 & 23.77 & 0.001 \\
\hline $25-29$ & 28 & 66.7 & 14 & 33.3 & & \\
\hline $30-34$ & 2 & 40 & 3 & 60 & & \\
\hline
\end{tabular}

\section{DISCUSSION}

The present study illustrates that more than $40 \%$ of respondents were married and had first child before age of 19 years. This result is consistent with the national data presented in Nepal Demographic Health Survey 2011. ${ }^{17}$ Similarly, in the present study, $85 \%$ of respondents were heard about uterus prolapse, however out which about $28 \%$ of respondent were not able to responses even single risk factors associated to uterus prolapse. Similarly, about $68 \%$ of respondents were not able to response any single most sign and symptoms of uterus prolapse. In the study, $70 \%$ of the respondents have responded doing heavy work during postnatal period is single most risk factor of uterus prolapse followed by frequent child bearing with less child spacing is also perceived as risk factors for uterus prolapse among respondents. Over all adequate knowledge on risks factors of UP among respondents found to be $46.5 \%$ and $53.5 \%$ of respondents showed inadequate knowledge regarding risk factors of uterus prolapse. Similar study conducted in different districts of Nepal revealed that nearly more than $50 \%$ were not heard about uterus prolapse and only $37.5 \%$ of women who have heard about uterus prolapse presented a satisfactory level of knowledge about UP risk factors, sign and symptoms. ${ }^{6}$ Also study conducted by Karki et al showed that $55.1 \%$ of the respondents were aware regarding the cause of utero-vaginal prolapsed $58.5 \%$ of respondents were aware regarding the sign and symptoms of utero-vaginal prolapsed. ${ }^{18}$ In addition, a qualitative study in India also showed that most women do not know the symptoms and risks factors of uterus prolapse. ${ }^{19}$

Likewise, the present study also explicitly reflects the knowledge on risks factors of uterus prolapse is significantly associated with the age of respondent $(\mathrm{p}=0.021)$, age at marriage of respondents $(\mathrm{p}=0.011)$, education status of respondents $(\mathrm{p}=0.001)$, age at first child birth of respondent $(\mathrm{p}=0.001)$. Results showed that 
older the age of respondent higher the level knowledge on risk factors of UP and those respondents who were married at early age before 19 years have comparatively less aware about risk factors of uterus prolapse. Similarly, higher the education status better the awareness level on risk factors of uterus prolapse was found. Study conducted by Shrestha et al also demonstrated that women's age group was associated with UP knowledge. Compared with women aged $<20$ years, the odds of having UP knowledge were 0.4 and 0.3 times higher in women aged 20-35 years and >35 years, respectively. The strengths of associations in multivariate and univariate models were similar, except the odds that women of the age group 20-35 years would have satisfactory knowledge were 0.4 and 0.7 , and that of the age group $>35$ years were 0.3 and 0.5 , respectively. ${ }^{6}$ The study results are consistent with the similar comparable studies from Nepal, India, Moscow and Vienna. ${ }^{6,18,20-22}$

\section{CONCLUSION}

In conclusion, majority of respondents have heard about uterus prolapse however very few participants have indepth or adequate knowledge about risk factors of uterus prolapse. Study clearly indicates that though government and non-governmental organizations have been working for early diagnosis treatment and prevention of uterus prolapse in Nepal since long time, still lot need to be done for expected achievement in preventing UP particularly among rural Nepalese women. It would be more effective if information regarding UP can be introduced on secondary level health education curriculum along with sexual and reproductive health content. Moreover Community based pragmatic interventions are equally important for both creating awareness; early diagnosis and treatment of UP to improve maternal health status of Nepalese women. Health workers at community level particularly at health post and Primary health care centre need more active involvement in creating awareness for prevention of uterus prolapse among rural Nepalese women.

\section{Funding: No funding sources}

Conflict of interest: None declared

Ethical approval: The study was approved by the Institutional Ethics Committee

\section{REFERENCES}

1. Walker GJA, Gunasekera P. Pelvic organ prolapse and incontinence in developing countries: review of prevalence and risk factors. Int Urogynecology $\mathrm{J}$. 2011;22(2):127-35.

2. Gunasekera P, Sazaki J, Walker G. Pelvic organ prolapse: don't forget developing countries. Lancet. 2007;369(9575):1789-90.

3. Kuncharapu I, Majeroni BA, Johnson DW. Pelvic organ prolapse. American family physician. 2010;81(9):1111-7.
4. Barber MD, Maher C. Epidemiology and outcome assessment of pelvic organ prolapse. Int Urogynecology J. 2013;24(11):1783-90.

5. Gurung G, Rana AA, Bista A, Joshi DK, Jamuna AB. Pelvic organ prolapse in rural Nepalese women of reproductive age groups: what makes it so common? Nepal J Obst Gynae. 2007;2(2):35-41.

6. Shrestha B, Devkota B, Khadka BB. Knowledge on uterine prolapse among married women of reproductive age in Nepal. Int $\mathrm{J}$ Women Health. 2014;6:771-9.

7. Unnecessary burden: gender discrimination and uterine prolapse in Nepal. Available at file:/// C:/Users/india/Downloads lasa310012014en.pdf. Accessed on 12 February 2016.

8. Clinical Protocol for Management of Pelvic organ Prolapse: Clinical Protocol. Kathamndu. Family Health Division, Government of Nepal. 2012.

9. Institute of Medicine. Reproductive morbidity report on clinic based survey: status of reproductive morbidities in Nepal. Kathamndu. 2006.

10. Shrestha ADL, Sharma B, Jyoti. Prevalence of uterine prolapse amongst gynecology OPD patients in Tribhuvan University teaching hospital in Nepal and its socio- cultural determinants. Kathmandu, Nepal. 2012.

11. NAPOPM-Nepal. National alliance for pelvic organ prolapse management-Nepal: Nepal jointsubmission to the United Nations committee on economic, social and cultural rights. Kathamndu. 2014.

12. Gyhagen M, Bullarbo M, Nielsen TF, Milsom I. Prevalence and risk factors for pelvic organ prolapse 20 years after childbirth: a national cohort study in singleton primiparae after vaginal or caesarean delivery. BJOG. Int J Obst Gynae. 2013;120(2):15260.

13. Adler BB, Shrivastava C, Bodner K. Risk factors for uterine prolapse in Nepal. Int Urogyne J Pelvic Floor Dysfunction. 2007;18(11):1343-6.

14. Nepal demographic and health survey 2011. Available at http:// dhsprogram.com /pubs/pdf /FR257/FR257\%5B13April2012\%5D.pdf. Accessed on 12 February 2016.

15. UNFPA. Health related quality of life of women suffering from pelvic organ prolapse: before and 9 to 11 months after surgical interventions. Lalitpur, Nepal. Available at http:// nepal.unfpa.org /sites /asiapacific/files/pub-pdf/UNFPA-QualityBookFinal-ALL.pdf.2013. Accessed on 12 February 2016.

16. Radl CMR, Aro R. Uterine prolapse prevention in Eastern Nepal: the perspectives of women and health care professionals. International $\mathrm{J}$ Womens Health. 2012;4:373-82.

17. Ministry of Health and Population (MOHP). ICF International Inc. Nepal Demogrpahic Health Survey 2011. Calverton, Maryland. 2012.

18. Sita KA, Neraula. Awareness regarding uterovaginal prolapse among newar parous women. Int J Nursing Research Practice. 2014;1(1):15-9. 
19. Ragini KS, Chauhan. Socio-cultural aspects of reproductive morbidities among rural women in districts of Maharastha, India. Journal Family Welfare. 2009;55(2):27-33.

20. Shrestha BO, Choulagai B, Shrestha KB, Petzold M, Krettek A. Knowledge, prevalence and treatment practices of uterine prolapse among women of reproductive age in the Jhaukhel- Duwakot health demographic surveillance site, Bhaktapur, Nepal. J Kathamndu Med College. 2014;3(4):136-43.

21. Baruwal AS, Pradhan R, Samita. Knowledge, attitude and preventive measures amongst married women of reproductive age towards uterine prolapse in the eight villages of surkhet district of Nepal. J Health Res. 2011;25(3):129-34.
22. Lyatoshinskaya P, Gumina D, Popov A, Koch M, Hagmann M, Umek W. Knowledge of pelvic organ prolapse in patients and their information-seeking preferences: comparing Vienna and Moscow. Int Urogyne J. 2016:1-8.

Cite this article as: Singh DR, Lama S, Maharjan S. Knowledge on risk factors of uterine prolapse among reproductive age group women of Bajrabarahi Municipality of Lalitpur, Nepal. Int J Reprod Contracept Obstet Gynecol 2016;5:3343-8. 